\title{
MOBILE BANKING ADOPTION ANALYSIS IN NORTH MACEDONIA USING TAM
}

\author{
Kalina Trenevska Blagoeva \\ Faculty of Economics - Skopje, Ss. Cyril and Methodius University \\ kalina@eccf.ukim.edu.mk \\ Marina Mijoska Belsoska \\ Faculty of Economics - Skopje, Ss. Cyril and Methodius University \\ marina@eccf.ukim.edu.mk \\ Marija Trpkova-Nestorovska \\ Faculty of Economics - Skopje, Ss. Cyril and Methodius University \\ marija.trpkova-nestorovska@eccf.ukim.edu.mk
}

\begin{abstract}
Followed by the mobile technology development and high rate of mobile internet usage worldwide, mobile banking has become prominent technological innovation in the banking sector giving a competitive edge over traditional banking. Smartphones and mobile technologies are becoming increasingly available and affordable in North Macedonia in recent years, and many banks are providing banking services to customers via smartphones. The adoption of mobile banking in the country has not reached its full potential yet and has been at its early stage of adoption. However, not many studies investigate determinants of mobile banking adoption which may help banks to design more suitable mobile services for customers and increase the m-banking adoption in the country. This study is the first attempt to fill this gap by examining determinants that affect consumer intention to use mobile banking services in the country, as developing country. To get insights regarding the user adoption of m-banking services in the country, a survey was conducted among more than 150 mobile users. This study proposes a mobile banking user adoption research model based on the Technology Acceptance Model (TAM), and beside basic constructs (perceived ease of use, perceived usefulness and behavioral intention to use) it integrates social image, trust and risk that are specific for $m$ banking. The results of the empirical study are supporting the proposed basic constructs of the model and some specific relationships are unveiled. This research is a holistic approach representing a solid base for future studies on the adoption of new technologies in the country. Its originality and practical implications are reflected in determining the significance of additional constructs that are specific for m-banking. From practitioner's viewpoint, this research offers valuable insights for developing m-banking solutions.
\end{abstract}

Keywords: Mobile Banking, Technology Acceptance Model, Republic of North Macedonia.

JEL classification: M15, C52, G20, O30.

\section{INTRODUCTION}

Smartphones have become omnipresent devices and an integral part of citizens' living and doing business. The speed of the mobile technology innovation and pace of adoption is directly in relation to mobile banking. Mobile banking has become prominent technological innovation in

http://doi.org/10.47063/EBTSF.2020.0023

http://hdl.handle.net/20.500.12188/9701 
the banking sector giving a competitive edge over traditional banking. Banks are increasingly investing in mobile channels by providing new mobile banking services.

Various terms refer to mobile banking like m-banking, branchless banking, m-payments, mtransfers, m-finance, or pocket banking (Shaikh and Karjaluoto, 2015). M-banking refers to provision of banking and financial services with the help of mobile telecommunication devices such as a smartphone or tablet (Chandran, 2014), like viewing account balances, making transfers between accounts, or paying bills. The scope of offered services may differ, but generally includes facilities to conduct bank transactions, to administer accounts and to access customized information. Mobile banking provides customers with 24-hour access to account balances and transaction histories. One can use mobile banking to deposit checks anytime, pay bills, check payment history by date and description, transfer money directly to other people, and make loan payments. M-banking can take place through short message service (SMS), mobile web or application. It is developed to support the clients in using various banking services, by using their mobile phones, thus allowing them to overcome the barriers in terms of time and location (Pejic Bach et.al., 2020). M-banking users can perform almost the same transactions of internet banking by using a mobile device (Shaikh and Karjaluoto, 2015). M-banking and internet banking are commonly perceived as two similar alternative self-service channels for banks to deliver products and services for their customers (Thakur, Srivastava, 2014).

Mobile banking usage statistics over the years show that, banking trends have swung firmly in the direction of mobile banking now that more than half of the world's population own a smartphone. The mobile app market will generate a revenue of $\$ 581.9$ billion in 2020 (Statista, 2020). Experts predict that mobile payments will grow at a CAGR of $80 \%$ throughout 2020 , reaching an annual total of $\$ 503$ billion (Business Insider, 2019). Mobile banking UK statistics reveal that this country is the European leader in mobile payments, with $74 \%$ of its population using mobile devices to manage their finances (Dataprot, 2020).

Despite this growing popularity, some countries still fall short on the demand for mobile tasks, like bill pay and reward redemption, causing them to push users to online banking. Mobile banking services have not been widely used by most bank customers in North Macedonia. Most bank customers continue to conduct most of their banking transactions using traditional methods. To understand the reasons behind the actual adoption of m-banking, in the country, this study identifies factors that affect customers' usage of mobile banking services. The type of research applied in this study is exploratory in nature. A research model was developed by integrating the constructs of Technology Acceptance Model (TAM) and some specific constructs for the mbanking domain. Sub objectives of this research assess the relationship of independent variables, Perceived Usefulness, Perceived Ease of Use, Social Image, Perceived Trust and Perceived Risk with dependent variable, behavioral intention. A total of 175 actual and potential users of mbanking services were used as a sample. A well-structured questionnaire was used to collect the relevant information administrated both online and offline. The data is analyzed using regression analysis. The results of this research provides insights on individual user attitude towards adoption phase of mobile banking. Understanding m-banking's consumer attitude may help both researchers and service providers to develop strategies to attract potential adopters and retain users. Banks in the country are well aware that smartphones are becoming the favorite personal devices and gadgets of the macedonian population in particular, thus, this research offers valuable insights for developing better m-banking solutions. This research is among the first in the country that investigate the determinants that affect mobile banking adoption in North Macedonia using TAM based model. 
The structure of the paper is as follows. In the first section, theoretical background we describe available theories of technology adoption. We then present the research model and hypothesis. The next section define the research model and data collection, followed by data analysis and results. Finally, the conclusions and recommendations are made.

\section{THEORETICAL BACKGROUND}

Understanding of consumer behaviour is fundamental insight for decision making for every aspect of business. Consumer behavior can be broadly defined as the decisions and actions that determine the purchasing behavior of a consumer. The study of consumer behavior not only helps to understand the past but even predict the future. Since using certain technology represent ones behavioural act, models that originate from behavioural psychology are compatible when analyzing different factors that determine consumer behavior.

A number of theories are proposed to explain consumers' adoption of new technologies and their intention to use. Theories of adoption of new technologies are explanations (and discovery) of the factors that influence the decision making over adoption and usage of new technologies by the users (individuals or corporate). Adoption in the context of mobile banking means acceptance and being able to accept a new technology as it is introduced; acceptance of the service means a customer willing to use the service. Theories and models that investigates successful technology diffusion can be categorized in various ways. According to Hilmer (2009), common technology adoption theories, can be grouped as: Diffusion Theories, User Acceptance Theories, Decision Making Theory (including Problem Solving Theories), Personality Theories and Organisation Structure Theories (Hillmer, 2009). The most commonly used in the academic world are the Theory of Reasoned Action (TRA), the Theory of Planned Behaviour (TPB), the Technology Acceptance Models (TAM), and the Unified Theory of Acceptance and Use of Technology (UTAUT) (Hillmer, 2009).

There are several theories and subsequent models that are in broad use to measure end users' acceptance of a new technology since 1990s, but the most widely used are Technology Acceptance Model (TAM) (Davis, 1989) and Unified Theory of Acceptance and Use of Technology (UTAUT) (Venkatesh, Morris, Davis \& Davis, 2003). Davis's Technology Acceptance Model (TAM) is one of the most renewed approaches to explain and predict user acceptance of information systems (Davis, 1989). According to Davis (1989), the goal of TAM is "to provide an explanation of the determinants of computer acceptance that is generally capable of explaining user behaviour across a broad range of end-user computing technologies and user populations, while at the same time being both parsimonious and theoretically justified" (p. 985). This model is based on the assumption that the major factors influencing intention to use any technology are predicted by two so called constructs: perceived usefulness and perceived ease of use (Davis, Bagozzi and Warshaw, 1989). The goal of Davis' (1989) TAM is to explain the general determinants of computer acceptance that lead to explaining users' behaviour across a broad range of end-user computing technologies and user populations. The basic TAM model included and tested two specific beliefs: Perceived Usefulness (PU) and Perceived Ease of Use (PEU). Perceived Usefulness is defined as the potential user's subjective likelihood that the use of a certain system (single platform E-payment System) will improve his/her action and Perceived Ease of Use refers to the degree to which the potential user expects the target system to be effortless (Davis, 1989). The perceived usefulness of a technology increases with perceived ease of use. In the TAM related literature, four of the most important constructs that have been constantly used are the perceived ease of use, perceived usefulness, behavioural intention and 
actual usage behavior as the outcome construct. The more ease of use a user thinks a new technology is, the stronger his or her intention to use the technology; furthermore, the stronger the usage intention, the greater the actual usage behaviour. TAM model is by no means a general model; and it is designed to be applied only to computer usage behavior (Davis, 1989). Therefore, the application of TAM model is appropriate for research purposes while studying adoption of mobile banking.

Venkatesh and Davis (2000) proposed the TAM 2. TAM 2 explains PU in terms of two external variables namely 'social influence processes' and 'cognitive instrumental processes' which has proven to be significantly influenced user acceptance (Venkatesh and Davis, 2000). The social influence processes include subjective norms (as in TRA), voluntariness, social influence, images, and experience, while the cognitive instrumental process includes job relevance, output quality, result demonstrability, and PEOU. The operational definitions of the variables constructing 'social influence processes' are; (1) 'Subjective norms' is defined as "person's perception that most people who are important to him think he should or should not perform the behavior in question" (2) Voluntariness is defined as "the extent to which potential adopters perceive the adoption decision to be non-mandatory", (3) Social influence is defined as "influence to accept information from another as evidence about reality", and (4) Images is defined as "the degree to which use of an innovation is perceived to enhance one'status in one's social system" (Venkatesh and Davis, 2000). Venkatesh and Bala (2008) combined TAM2 (Venkatesh and Davis, 2000) and the model of the determinants of perceived ease of use (Venkatesh, 2000), and developed an integrated model of technology acceptance known as TAM3. The authors developed the new model using four different determinants including the individual differences, system characteristics, social influence, and facilitating conditions which are determinants of perceived usefulness and perceived ease of use. Even though TAM has been tested widely with different samples in different situations and proved to be valid and reliable model explaining information system acceptance and use many extensions to the TAM have been proposed and tested (Venkatesh and Davis, 2000; Lai, 2018).

\section{RESEARCH MODEL AND HYPOTHESIS}

The research model in this survey is based on TAM2 (Venkatesh and Davis, 1996). This model provides a framework for explaining and predicting technology use. TAM is a generic model that can facilitate the explanation of the factors that influence technology adoption, or in our case mobile banking behavior. The final version of Technology Acceptance Model, formed by Venkatesh and Davis, after the main finding of both perceived usefulness and perceived ease of use were found to have a direct influence on behaviour intention, thus eliminating the need for the attitude construct. However, there are many extensions to the basic model and we are using some additional constructs that are proven to be essential for explaining mobile banking adoption. Basic constructs that we examined are: Perceived usefulness, Perceived ease of use and Behavioral Intention to use. As extensions of the original model, we added three more constructs: Perceived Risk, Perceived Trust and Social Image, proven to be determinants on mobile banking adoption. 


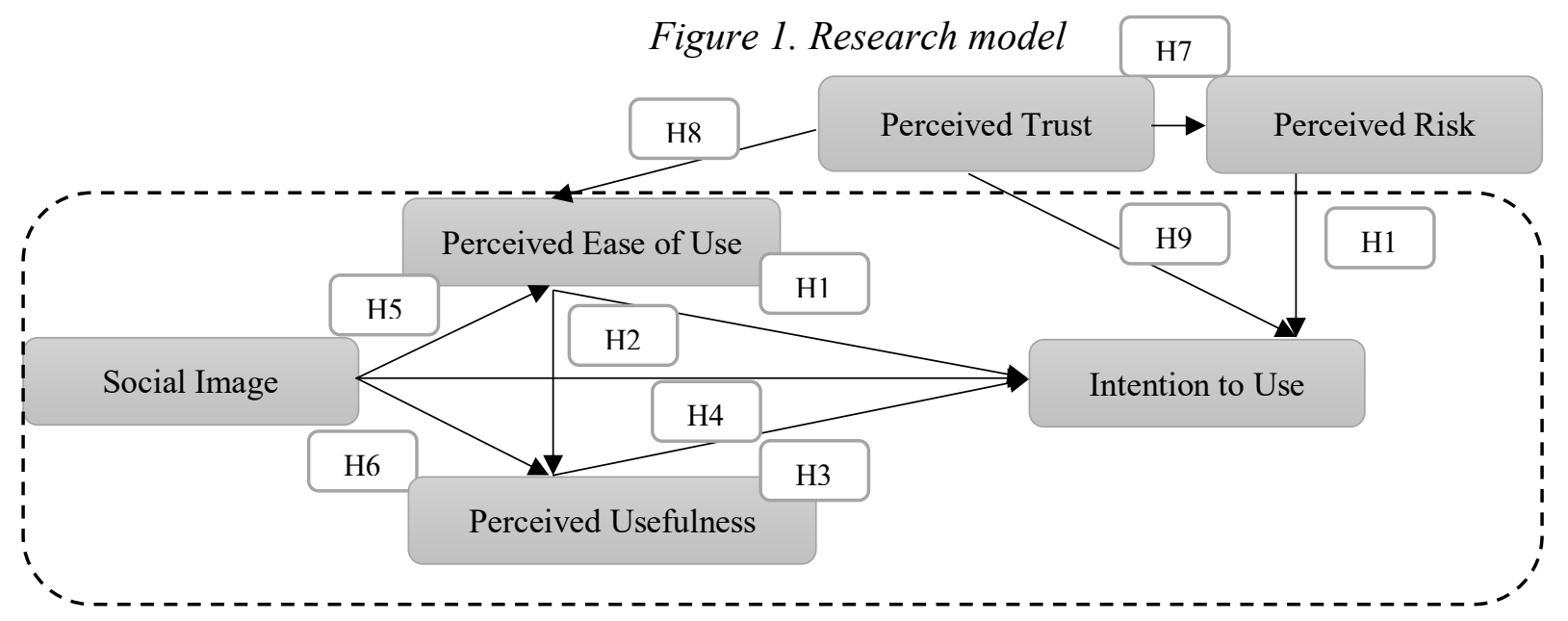

Perceived risk is the "uncertainty about the outcome of the use of the innovation" (Gerrard, and Cunningham, 2003). Because of the open nature of internet and the spatial and temporal separation between user and bank, mobile banking operation is under an uncertainty transaction infrastructure and this make the customer face the risk of financial loss and privacy threaten. (Song, 2015). Many authors have studied the impact of risk on the adoption of mobile banking building upon the premise that $\mathrm{m}$-banking is perceived to be riskier than traditional banking (Gerrard, and Cunningham, 2003; Cunningham et al., 2005: Song, 2015). Luo, Li, Zhang, and Shim (2010) analyzed the impact of both trust and risk in $\mathrm{m}$ - banking adoption. Perceived Trust is an important catalyst in many transactional relationships, and it determines the nature of many businesses. According to Yousafzai et.al, (2003), trust is perhaps the most important component of electronic banking transaction. Perception of trust is likely to be important factors that influence consumers' behavior intention to adopt mobile banking.

It is considered that, innovation in general, can provide users with a sense of uncertainty about the consequences of consumption, pushing users to seek advice from others for opinions and personal experiences. Therefore, social image is considered important factor in technology adoption (Munoz-Leiva et.al., 2017). According to Song (2015), mobile banking is the combination of information system and self-service under wireless networks context. The mobile banking adoption intention of users may be influenced by the perceived usefulness and perceived ease of use as the other information systems, but the social image which may affect the customer's behavior intention (De Leon, 2019). Social image can be explained as the "extent to which users may derive respect and admiration from peers in their social network as a result of their IT usage" (Lin and Bhattacherjee, 2010). Social image is considered as capable of influencing the ease of use of advanced mobile services (Bouwman et al., 2008).

Based on the discussion above, in this empirical study, the proposed research model which is based on the technology acceptance model (TAM) as the basic theoretical model, is adjusted/extended with social image, perceived trust and perceived risk in order to predict the customers' adoption intention of mobile banking. This model includes ten hypotheses (Figure 1).

\section{RESEARCH METHOD AND DATA COLLECTION}

For the analysis in this paper, where attitudes of the current potential mobile banking users are examined, authors designed the research in two segments: the first step was to create a structured questionnaire entailing the TAM model characteristics, in order to create reliable constructs that 
can be used in the second segment, the regression analysis. Similar approach was implemented in Luo, Li, Zhang, and Shim (2010), Aboelmaged and Gebba (2013), Song, H.L. (2015), MunozLeiva, F., Climent-Climent, S. and Liébana-Cabanillas, F. (2017), De Leon, M.V. (2019).

The design of this research can also be implemented by using exploratory and confirmatory factor analysis, followed by structural equation modeling. There is a research where multidimensional scaling and $\chi^{2}$ tests are used to assess the difference between the variables (Cruz et al., 2010). TAM based models and their application are widely used by numerous authors in their research, with different combinations of research tools. Yet, authors decided to follow the examples of already published research where the combination of testing of construct reliability and regression analysis was used and confirmed to provide satisfactory results on the examined issue.

A questionnaire was developed to be the instrument for data collection, adopted from basic TAM and confirmed by significant research. The idea was to create a sample that will include different type of respondents according to age, gender, and education level and employment status that are online active. It has been recognized in general that youth are very representative sample of today's online population in the country. Population of interest in this research are different groups who are adopting and using mobile banking: young people (mostly students) aged 18-24, young employed people aged 25-35 and more mature employed professionals over 35 years of age. The data were collected at the university campus and from the different sectors of the business community. Thus, part of this anonymous survey was conducted online, and the other part was person to person with hard-copy questionnaires during December 2019 and May 2020 targeting around 200 mobile users.

The items that were chosen for measuring of each variable are as follows: Perceived usefulness (3 items): M-banking improves my work and life efficiency. M-banking allows me to easily acquire the information/service I need. Overall, m-banking is useful; Perceived ease of use (3 items): I think that it is easy to use m-banking to accomplish my banking tasks. Learning to use $\mathrm{m}$-banking is easy for me. It is easy for me to become skillful at using m-banking; Intention to use (3 items): I intend to use $\mathrm{m}$-banking in the future. I will regularly use $\mathrm{m}$ - banking in the future. I intend to increase my use of mobile services in the future; Social image (3 items): The people around me who use m-banking have more prestige than those who do not use it. The people around me who use $\mathrm{m}$-banking have a higher status. Using $\mathrm{m}$-banking is a status symbol in my environment; Perceived risk (4 items): When using m-banking, I believe my information is kept confidential. When using m-banking, I believe my transactions are secured. When using m-banking, I believe my privacy would not be divulged. I do not incur in the risk of financial losses using m-banking services.); Perceived trust (4 items): I do not trust using mobile device for m-banking. I am afraid of the inherent fraud and hacking associated with $\mathrm{m}$-banking. I am worried other people may access my account when using m-banking. It's risky to store banking info on a mobile device. Five-point Likert scale was included with level of agreement from 1Strongly disagree, 2- Disagree, 3-Neither agree nor disagree, 4-Agree, and 5-Strongly agree.

\section{DATA ANALYSIS AND RESULTS}

This study tries to examine different influences on mobile banking usage via extended TAM model. Data for this survey were collected at the University campus (students) and respondents employed at various sectors of the business community in the country. Population of interest are respondents from different age groups who are in process of adopting or using mobile banking. 
The sample is comprised of 175 survey responses. Their demographic structure is presented in Table 1.

Table 1. Demographic structure of the respondents

\begin{tabular}{|c|c|c|c|}
\hline VARIABLE & VARIABLE CATEGORIES & FREQUENCY & PERCENTAGE \\
\hline \multirow{2}{*}{ Gender } & Female & 101 & 57.7 \\
\hline & Male & 74 & 42.3 \\
\hline \multirow{3}{*}{ Age } & $18-24$ & 78 & 44.6 \\
\hline & $25-35$ & 30 & 17.1 \\
\hline & Above 35 & 67 & 38.3 \\
\hline \multirow{3}{*}{ Education } & High school degree & 11 & 6.3 \\
\hline & Student & 75 & 42.9 \\
\hline & University graduate & 89 & 50.9 \\
\hline \multirow{2}{*}{$\begin{array}{l}\text { Employment } \\
\text { status }\end{array}$} & Unemployed & 100 & 57.1 \\
\hline & Employed & 75 & 42.9 \\
\hline CONSTRUCTS & ITEMS (questions) & FREQUENCY & PERCENTAGE \\
\hline \multirow{5}{*}{$\begin{array}{c}\text { Usage } \\
\text { frequency of } \\
\text { mobile banking }\end{array}$} & Every day & 29 & 16.6 \\
\hline & At least once a week & 69 & 39.4 \\
\hline & At least once a month & 33 & 18.9 \\
\hline & Very little (at least once at six months) & 26 & 14.8 \\
\hline & Have not use mobile banking & 18 & 10.3 \\
\hline \multirow{4}{*}{$\begin{array}{l}\text { Usual access } \\
\text { point for mobile } \\
\text { banking }\end{array}$} & Via smartphone (mobile web) & 47 & 26.9 \\
\hline & Via smartphone with mobile application & 107 & 61.1 \\
\hline & Via Tablet & 3 & 1.7 \\
\hline & Have not use mobile banking & 18 & 10.3 \\
\hline
\end{tabular}

\section{(Source: Authors calculations)}

The survey was fully completed, and there was no missing data and presence of outliers. Since Items (questions) are represented by ordinal data, interval data Variables are derived by calculation of an average score for appropriate group of items, for each respondent. Thus, new variables or constructs are created, consisted of the calculated scores. To use appropriate constructs as variables in the regression models, it was essential to first test the constructs for their reliability. Reliability, as defined by Field (2005), means that a scale should consistently reflect the construct it is measuring. Questionnaire was constructed to develop seven variables. To confirm their reliability, Cronbach's $\alpha$ was calculated by the following formula:

$$
\alpha=\frac{k \times \bar{c}}{\bar{v}+(k-1) \bar{c}}
$$

where $k$ is the number of scale items, $\bar{c}$ is the average of all covariances between items and $\bar{v}$ is the average variance of each item. The results of the reliability analysis and the defined variables are presented in Table 2.

As the research model indicates, there are six constructs derived as variables for the regression model. All the variables can be included in regression models, as their reliability coefficients are greater than 0.7 which is acceptable value for reliable scale (Hair at al., 2005). 
Table 2. Scale reliabilities for defined variables

\begin{tabular}{|l|c|}
\hline VARIABLE & CRONBACH'S $\boldsymbol{\alpha}$ \\
\hline Perceived Usefulness & 0.808 \\
\hline Perceived Ease Of Use & 0.788 \\
\hline Intention To Use & 0.848 \\
\hline Perceived Trust & 0.864 \\
\hline Social Image & 0.866 \\
\hline Perceived Risk & 0.895 \\
\hline
\end{tabular}

(Source: Authors calculations based on survey data)

To gain an insight of the variables, their descriptive statistics are calculated. Variables Perceived usefulness, Perceived ease of use and Intention to use have high average values, approximately 4.4, implying that they highly agree with most of the questions, or they perceive mobile banking useful, easy to use and their intent is to use mobile banking further. This is also confirmed by their skewness coefficients, which show negative skewness, meaning high frequency of the answers is concentrated on the right side of the histogram, or answers graded 4 and 5 (agree and strongly agree, respectively).

Perceived risk has lower mean value than previously mentioned variables, it is 3.7 , and it also has negative skewness. Most of the answers of this variable are around 4 (agree) and 3 (neutral). This suggests that the respondents do not feel completely safe when using mobile banking, they still have certain reservations.

Variable Perceived trust has average value of 3.06 and skewness very close to 0 , indicating that significant part of the answers is neutral. This implies that respondents still have trust issues, they are not completely certain that mobile banking is secure, they are afraid of frauds and unauthorized access of their accounts.

Social image proves to be not relevant for mobile banking. With low mean value of 2.59 and positive skewness, most of the respondents do not agree using mobile banking will provide them with prestige and higher status. Probably mobile banking is more practical than image issue.

Table 3. Descriptive statistics for the created variables

\begin{tabular}{|l|r|r|r|r|}
\hline \multicolumn{1}{|c|}{ Variable } & \multicolumn{1}{c|}{ Mean } & \multicolumn{1}{c|}{$\begin{array}{c}\text { Standard } \\
\text { deviation }\end{array}$} & \multicolumn{1}{c|}{ Skewness } & \multicolumn{1}{c|}{ Kurtosis } \\
\hline Perceived usefulness & 4.41 & 0.77 & -1.979 & 4.878 \\
\hline Perceived ease of use & 4.44 & 0.62 & -1.189 & 1.358 \\
\hline Intention to use & 4.47 & 0.76 & -2.115 & 6.004 \\
\hline Trust & 3.06 & 1.11 & -0.015 & -0.848 \\
\hline Social image & 2.59 & 1.12 & 0.309 & -0.649 \\
\hline Risk & 3.70 & 0.88 & -0.647 & 0.244 \\
\hline
\end{tabular}

(Source: Authors calculations based on survey data)

\subsection{Testing hypotheses of the research model}

As presented in Figure 1, the research model entails number of hypotheses with different relations between variables as dependents or/and independents that follow the TAM model. These relations are defined as research hypotheses. Before performing the regression analysis, Pearson's correlation coefficients and two tailed tests of significance are calculated (Table 4). These coefficients are calculated in order to identify the statistically significant relationships between variables (constructs) that only follow and are in accordance with the TAM model: 
H1: Perceived ease of use is linearly related to Intention to use - correlation coefficient of 0.521 , statistically significant at 0.01 level;

$\mathrm{H} 2$ : Perceived ease of use is linearly related to Perceived usefulness - correlation coefficient of 0.599 , statistically significant at 0.01 level;

H3: Perceived usefulness is linearly related to Intention to use - correlation coefficient of 0.573 , statistically significant at 0.01 level;

H4: Social image is linearly related to Intention to use - correlation coefficient of -0.036 , statistically not significant;

H5: Social image is linearly related to Perceived ease of use - correlation coefficient of 0.145 , statistically not significant;

H6: Social image is linearly related to Perceived usefulness - correlation coefficient of 0.130 , statistically not significant;

H7: Perceived trust is linearly related to Perceived risk - correlation coefficient of -0.321 , statistically significant at 0.01 level;

H8: Perceived trust is linearly related to Perceived ease of use - correlation coefficient of -0.0185 , statistically significant at 0.05 level;

H9: Perceived trust is linearly related to Intention to use - correlation coefficient of 0.154 , statistically significant at 0.05 level;

H10: Perceived risk is linearly related to Intention to use - correlation coefficient of 0.351 , statistically significant at 0.01 level.

Table 4. Pearson's Correlation Analysis

\begin{tabular}{|c|c|c|c|c|c|c|c|}
\hline & Variables & $\begin{array}{l}\text { Perceived } \\
\text { usefulness }\end{array}$ & $\begin{array}{l}\text { Perceived } \\
\text { ease of use }\end{array}$ & $\begin{array}{c}\text { Intention of } \\
\text { use }\end{array}$ & $\begin{array}{c}\text { Perceived } \\
\text { trust }\end{array}$ & $\begin{array}{l}\text { Social } \\
\text { image }\end{array}$ & $\begin{array}{c}\text { Perceived } \\
\text { risk }\end{array}$ \\
\hline \multirow{2}{*}{$\begin{array}{l}\text { Perceived } \\
\text { usefulness }\end{array}$} & Pearson Correlation & 1 & $0.599^{* *}$ & H3 $0.573^{* *}$ & -0.033 & -.0130 & $0.205^{* * *}$ \\
\hline & Sig. (2-tail & & 0.000 & 0.000 & 0.663 & 0.087 & 0.007 \\
\hline \multirow{2}{*}{$\begin{array}{c}\text { Perceived ease } \\
\text { of use }\end{array}$} & Pearson Correl & H2 $0.599^{* *}$ & 1 & H1 $0.521^{* *}$ & $-0.185^{*}$ & -0.145 & $0.313^{* * *}$ \\
\hline & Sig. (2-tailed) & 0.000 & & 0.000 & 0.014 & 0.055 & 0.000 \\
\hline \multirow{2}{*}{ Intention of use } & Pearson Correl & $0.573^{* *}$ & $0.521^{* *}$ & 1 & $-0.154^{*}$ & -0.036 & $0.351^{* * *}$ \\
\hline & Sig. (2-tailed) & 0.000 & 0.000 & & 0.042 & 0.635 & 0.000 \\
\hline \multirow{2}{*}{ Perceived trust } & Pearson Correlation & -0.033 & H8 $-.0185^{*}$ & H9 $-0.154^{*}$ & 1 & 0.106 & H7 $-0.321^{* * *}$ \\
\hline & Sig. (2-tai & 0.663 & 0.014 & 0.042 & & 0.164 & 0.000 \\
\hline \multirow{2}{*}{ Social image } & Pearson Cor & H6 -0.130 & H5 -0.145 & H4 -0.036 & 0.106 & 1 & -0.038 \\
\hline & Sig. (2-taile & 0.087 & 0.055 & 0.635 & 0.164 & & 0.617 \\
\hline \multirow[t]{2}{*}{ Perceived risk } & Pearson Corr & $0.205^{* *}$ & \multicolumn{2}{|c|}{$0.313^{* *} \mid \begin{array}{l}\mathrm{H} 10 \\
0.351^{* *}\end{array}$} & $-0.321^{* *}$ & -0.038 & \\
\hline & Sig. (2-tailed) & 0.007 & 0.000 & 0.000 & 0.000 & 0.617 & \\
\hline
\end{tabular}

**Correlation is significant at the 0.01 level

*Correlation is significant at the 0.05 level

(Source: Authors calculations based on survey data)

Out of ten defined hypotheses, three (H4, H5 and H6) do not have significant correlation coefficients, implying that there is a low probability of statistically significant relationship in the regression model. These hypotheses stem from the variable Social image.

The results from the ten regression models testing the hypotheses are presented in Table 5. In accordance to the results from the correlation matrix, the hypotheses H4, H5 and H6 include relationships that are not statistically significant, or social image does not have an influence on 
intention to use, perceived ease of use and perceived usefulness, respectively. As previously interpreted results from Table 3 say that mobile banking is not really influence by the social image, the regression only confirms these previous assumptions. Overall, social image does not have significant contribution in motivation of the consumers to use mobile banking, according to the data of this survey. Remaining seven hypotheses confirm existing relationships, as defined. Perceived ease of use has positive and statistically significant influence on intention to use and on perceived usefulness ( $\mathrm{H} 1$ and $\mathrm{H} 2$ ). Perceived usefulness has statistically significant and direct impact on intention to use (H3). Perceived trust has statistically significant and inverse influence on the perceived risk, perceived ease of use and intention to use (H7, H8 and H9). Perceived risk has statistically significant direct impact on intention to use (H10).

Table 5. Single regression models for analyzed variables

\begin{tabular}{|l|c|r|r|r|}
\hline \multicolumn{1}{|c|}{ Variable } & Coef. & Std. Error & \multicolumn{1}{c|}{ t-stat. } & \multicolumn{1}{c|}{ Sign. } \\
\hline H1: Perceived ease of use influences Intention to use & 0.638 & 0.080 & 8.020 & $0.000^{* *}$ \\
\hline H2: Perceived ease of use influences Perceived usefulness & 0.745 & 0.076 & 9.842 & $0.000^{* *}$ \\
\hline H3: Perceived usefulness influences Intention to use & 0.564 & 0.061 & 9.189 & $0.000^{* *}$ \\
\hline H4: Social image influences Intention to use & -0.025 & 0.052 & -0.475 & 0.635 \\
\hline H5: Social image influences Perceived ease of use & -0.081 & 0.042 & -1.934 & 0.055 \\
\hline H6: Social image influences Perceived usefulness & -0.089 & 0.052 & -1.719 & 0.087 \\
\hline H7: Perceived trust influences Perceived risk & -0.255 & 0.057 & -4.448 & $0.000^{* *}$ \\
\hline H8: Perceived trust influences Perceived ease of use & -0.103 & 0.042 & -2.475 & $0.014^{*}$ \\
\hline H9: Perceived trust influences Intention to use & -0.105 & 0.051 & -2.050 & $0.042^{*}$ \\
\hline H10: Perceived risk influences Intention to use & 0.303 & 0.062 & 4.914 & $0.000^{* *}$ \\
\hline
\end{tabular}

**Coefficient is significant at the 0.01 level

*Coefficient is significant at the 0.05 level

(Source: Authors calculations based on survey data)

\subsection{Discussion}

The research model includes number of interrelationships between variables, all in function to determine the main factors of intention to use mobile banking. As previous results confirm, Perceived ease of use and Perceived usefulness (H1 and H3) are variables that have statistically significant and positive influence on the Intention to use mobile banking. Respondents consider mobile banking to improve work and life efficiency, it allows easier access to necessary information or service, they find it easy to use, efficient and useful. Also, Perceived ease of use has statistically significant and positive impact on the Perceived usefulness $(\mathrm{H} 2)$. Mobile banking is perceived useful because one of its benefits is perceived ease of use (it is easy to learn, efficient in accomplishing banking tasks and it does not require much effort to become skillful at it).

Interesting, Social image is not very important to the respondents of this survey, they do not think that it has any influence on the Intention to use (H4), or on the Perceived ease of use (H5) and on the Perceived usefulness (H6). Social image includes perceptions such as that mobile banking gives prestige and higher social status to people who use it. There is no confirmed statistically significant coefficient with Social image as independent variable if any of the estimated regressions that include it. Apparently, social image is not considered as important factor that determines the use of mobile banking, it simply does not motivate the consumers to use it, according to the data of this survey. Contrary to Social image, Perceived trust is important determinant of mobile banking usage. As described in H7, Perceived trust has statistically 
significant influence on the perceived risk. The sign is negative because the questions for the variable Perceived trust are graded opposite to questions for other variables (in all variables grade 5 supports mobile banking, its ease of use, its usefulness, while in variable Perceived trust grade 5 means there is least confidence in mobile banking, thus the negative sign in the regression coefficients). Respondents find that having trust in the mobile device for mobile banking, feeling secure from fraud, hacking, or other unauthorized access reduces the Perceived risk of mobile banking usage (the information is kept confidential, transactions are secured, there are no risk of financial losses). Perceived trust influences Perceived ease of use (H8). With statistically significant coefficient in the regression, Perceived trust contributes to the perception of mobile banking as easy. Trust is just another component that encourages the users, current or new, to find mobile banking easy to use. Trust also influences the Intention to use (H9). When people are convinced that there is very low or no risk at all while governing their finances via mobile banking, they trust it, and are confident to use it further in the future. The regression confirmed statistically significant coefficient between these two variables.

Perceived risk has statistically significant direct impact on Intention to use (H10). Perceived risk and Perceived trust are probably two intertwined variables that influence the Intention to use mobile banking. If the risk is high, the trust is low, and there is no intention to use mobile banking, or, the risk is low, the trust is high, and there is an intent to use mobile banking. In this research the risk is considered low, so the respondents trust mobile banking and that contributes to their intention to use. When the information about personal finances remains confidential, privacy has not been breached, transactions are secured, and no financial losses occur, there is intent to use mobile banking in future.

\subsection{Research limitations and future research}

Some of the limitations of this study that could generate new lines of research for the future are mentioned further. We have to remain cautious when generalizing the results of this research since it uses a smaller sample. In order to overcome this limitation, the sample should be extended. Therefore, in future studies, it would be advisable to try to improve the representativeness of the sample and achieve generalization of the results from a larger sample nationwide. Additionally, data collection was carried out using both online and offline channels, a future research could be improved by using a unique approach. Also, for future studies, with larger samples for example, it is planned to analyze the moderating effect of demographic characteristics. Variables related to gender, age, social status, experience or user involvement with m-banking would be good examples, as well as the influence of the type of device, differentiating between smartphones and tablets etc. Another possible line of research would be to validate the model taking into account the socio-demographic characteristic traits and cultural differences of the respondents. The essence and nature of consumers' behavior is dynamic and complex, and therefore further research can be focused on longitudinal studies to compare changes in consumers' behaviors and explain different predictors.

\section{CONCLUSION}

M-banking is inevitable in conducting banking services not only in developed countries, but is gaining popularity in developing countries as well, especially in today's pandemic situation. The goal of this research is to identify the key determinates of consumer intention to use mobile banking services, by extending the TAM model with specific constructs which are hypothesized to influence intention to use mobile banking. Research hypotheses were tested using a single 
regression analysis. The results of the empirical study are supporting the proposed research model and some specific relationships are unveiled. Opposite of other related research, social image proves to be not relevant for mobile banking in our sample. Most of the respondents do not agree using mobile banking will provide them with prestige and higher status. Probably mobile banking is more practical than image issue. Social image does not have an influence on intention to use, perceived ease of use and perceived usefulness, respectively. Overall, social image does not have significant contribution in motivation of the consumers to use mobile banking, according to the data of this survey. Performing mobile payments is not considered a status symbol. All other variables in the model (perceived usefulness, perceived ease of use, perceived risk, and perceived trust) have statistically significant and positive influence on the intention to use mobile banking.

Finally, the results of the study shows the main managerial implications and provides indications for identification of certain strategies to reinforce this new banking model in the context of new technological advances.

\section{REFERENCES}

Aboelmaged, M. and Gebba, T.R., (2013), "Mobile banking adoption: an examination of technology acceptance model and theory of planned behavior". International Journal of Business Research and Development, 2(1).

Bouwman, H., de Vos, H. and Haaker, T. eds. (2008), Mobile service innovation and business models. Springer Science \& Business Media.

Chandran, R. (2014), "Pros and cons of mobile banking", International journal of scientific and research publications, Vol. 4 No.10, pp.1-5

Cruz, P., Neto, L. B. F., Munoz-Gallego, P., \& Laukkanen, T. (2010), "Mobile banking rollout in emerging markets: evidence from Brazil". The International Journal of bank marketing, 28(5), 342-371.

Cunningham, L. F., Gerlach, J. H., Harper, M. D., \& Young, C. E. (2005), "Perceived risk and the consumer buying process: internet airline reservations", International Journal of Service Industry Management, Vol. 16 No.4, 357 - 372

Davis, F. (1989), "Perceived Usefulness, Perceived Ease of Use, and User Acceptance of Information Technology", MIS Quarterly, Vol. 13 No. 3, p. 319-340.

De Leon, M.V. (2019), "Factors influencing behavioural intention to use mobile banking among retail banking clients", Jurnal Studi Komunikasi, Vol. 3 No. 2, pp.118-137.

Field, A. (2005), Discovering statistics using SPSS (2nd ed.), Thousand Oaks, CA, US: Sage Publications, Inc.

Hair, J. F., Black, W. C., Babin, B. J., Anderson, R. E., \& Tatham, R. L. (2006), Multivariate data analysis, Vol. 6, Upper Saddle River, NJ: Pearson Prentice Hall.

Hillmer, U. (2009), "Existing Theories Considering Technology Adoption. Technology Acceptance in Mechatronics", Gabler, pp. 9-28

Lai, P.C. (2018), "Research methodology for novelty technology", JISTEM-Journal of Information Systems and Technology Management, Vol. 15, pp.1-17

Lin, H.F. (2011), "An empirical investigation of mobile banking adoption: The effect of innovation attributes and knowledge-based trust", International journal of information management, Vol. 31 No. 3, pp.252-260 
Luo, X., Li, H., Zhang, J. and Shim, J.P. (2010), "Examining multi-dimensional trust and multifaceted risk in initial acceptance of emerging technologies: An empirical study of mobile banking services", Decision support systems, Vol. 49 No. 2, pp.222-234.

Munoz-Leiva, F., Climent-Climent, S. and Liébana-Cabanillas, F. (2017), "Determinants of intention to use the mobile banking apps: An extension of the classic TAM model", Spanish Journal of Marketing-ESIC, Vol. 21 No. 1, pp.25-38)

O'Dea, S. (2020), "Smartphone users worldwide 2016-2021”, Statista. https://www.statista.com/statistics/330695/number-of-smartphone-users-worldwide/

Pejić Bach, M., Starešinić, B., Omazić, M.A., Aleksić, A. and Seljan, S. (2020), “m-Banking Quality and Bank Reputation”. Sustainability, Vol. 12 No. 10, p.4315.

Shaikh, A.A. and Karjaluoto, H. (2015), "Mobile banking adoption: A literature review", Telematics and informatics, Vol. 32 No. 1, pp.129-142.

Song, H.L. (2015), Customer Adoption of Mobile banking: An integration of TAM with Trust and Social influence. In Applied Mechanics and Materials, Vol. 701, pp. 1323-1327. Trans Tech Publications Ltd.

Thakur, R. and Srivastava, M. (2014), "Adoption readiness, personal innovativeness, perceived risk and usage intention across customer groups for mobile payment services in India", Internet Research, Vol. 24 No. 3, pp. 369-392.

Venkatesh, V. and Bala, H. (2008), "Technology Acceptance Model 3 and a Research Agenda on Interventions", Decision Science, Vol. 39 No. 2, p. 273-312.

Venkatesh, V., Morris, M.G., Davis, G.B. and Davis, F.D. (2003), "User acceptance of information technology: Toward a unified view", MIS quarterly, pp.425-478.

Yousafzai, S.Y., Pallister, J.G. and Foxall, G.R., (2003), "A proposed model of e-trust for electronic banking”, Technovation, Vol. 23 No. 11, pp.847-860. 